\title{
Fusing interactive learning and display spaces in a heritage museum: The role of Architecture
}

\author{
Albert, Michael Tamunoibuomi ${ }^{\mathrm{a}}$, Warebi Brisibe Ph.D. ${ }^{\mathrm{b}}$ \\ ${ }^{\text {a } a l b e r t . m i c h a e l 702 @ g m a i l . c o m}{ }^{b}$ warebi.brisibe@ust.edu.ng \\ ${ }^{a}$ Postgraduate student, Department of Architecture, Rivers State University, Port Harcourt, Nigeria. \\ ${ }^{b}$ Head of Department, Department of Architecture, Rivers State Univeristy, Port Harcourt, Nigeria.
}

\begin{abstract}
The technological advancement of our age has shaped users' social, economic, physical, and psychological behaviours, creating patterns that have rippled over every sector of social life. The internet and other technological advancement have made life simpler and better for many people. The museum, a cultural institution responsible for preserving and presenting the tangible and intangible cultural heritage of man, has been unyielding to adapting to the march of technology as they appear to be on both sides of the extreme. Not until the focus shifted from object care to incorporating visitor care. Over the years, museum exhibitions have evolved with the advancement of technology. The display of cultural objects now utilise virtual navigation techniques, augmented reality (AR), virtual reality (VR), and the internet, with an aim of enriching the museum experience for visitors. This trend has influenced museum development and user behaviour. Architectural design plays a vital role in linking interactive learning and traditional displays in heritage museums. This paper focuses on the role of architecture in the use of interactive learning and display technologies in heritage museums, and how this role can accentuate the desire for museum users to have rich experiences.
\end{abstract}

Keywords: Architecture; Museum Display; Display technology; Museum experience; Interactive learning

\section{Introduction}

Today, museums, the institution dedicated to the acquisition, preservation, conservation, research and display of cultural objects have advanced beyond this traditional function. It is now involved in the life of its visitors, in an attempt to confront rapidly changing social, economic, and political needs (Sfintes, 2013). As Susan Crane (2006) states, the museum and its contents are being shaped by this change. Its role is significant in people's daily life. It serves as a connection between the past, the present, and the future. By interacting with the museum, one can better feel the charm of culture, cultivate interest in learning and improve one's overall quality (Wang and Liu, 2019). The museum creates an environment where art, science, history, and cultural objects are displayed to immerse the visitor and evoke emotions.

The turn of the century saw the introduction of digital technologies in the display of cultural objects creating another dimension in the relationship of artwork with physical space. The virtual museum system is an effective means of communicating cultural contents to visitors who can view digitized artworks and explore reconstructed historical places. The purpose is to create an entertaining, informative and enjoyable experience for visitors. Barbieri et al (2017) opine that the interactive displays offer more learning opportunities via educational games than in a physical museum environment. 


\section{History of technology inside museums}

The first handheld visitor technology was invented in 1952 with the aim of advancing an exclusive, individually controllable experience by its user. It was designed to be personal, available and suited to various learning styles not assisted by catalogues, text panel, or label. The handheld guide was first used at the Stedelijk Museum, in Amsterdam (Tallon and Walker, 2008). This was the first attempt at a new way of learning inside the museum's space. Critics saw this device as promoting isolation among visitors. In the 1960s, as a response, the social audio guide that included headphone sockets for two users was developed, and was used at the National Gallery of Art in Washington where it gained popularity above its predecessor. In the 1990s, a milestone was reached with the transition from analog to digital, which allowed the personalisation of tours through random and free access of content (Din and Hecht, 2007). The advent of the digital technology and the internet promoted the introduction of interpretive technology, such as the fixed-position gallery and the smart tables. This was used for the first time in 1999 at the Museum of Modern Art's (MoMA) exhibition called "Un-Private House." Composed of a circular table with a Radio Frequency Identification (RFID) tag, when users moved the images of one house' project its tag was read and suddenly appeared projection of floor plans, related video commentaries and other information about the subject(Din and Hecht, 2007). Inside the Churchill Museum is a "Lifeline Table" which is $15 \mathrm{~m}$ long, with a database of documents, pictures, letters and all the events related to Winston Churchill's life. The digital revolution, which is the period between the end of the $90 \mathrm{~s}$ and the early years of the $21^{\text {st }}$ century, saw a list of devices, which included the MP3, iPod, smartphones, and the iPhone, replacing the audio guide. Museums around the world started to have a digital department in charge of the technologies being used in the museum.

\subsection{The internet}

The advent of the internet seemed to contradict the identity of the museum. The museum is about the real while the internet is about the virtual, how could these extremes be brought together? The online experience is a substantial amplification of the museum's educational content. It is an opportunity for museums to expand its popularity, helping visitors to better understand exhibitions or in planning a visit. Online visitors and offsite visitors, have this in common. They can learn, teach, socialize, participate, shop, research and have fun. The COVID-19 pandemic affected international travels as well as museum visits worldwide. Many migrated to online museums, e-learning and the display of online collections. They connected with virtual visitors through the opportunities made possible by the internet (Antara and Sen, 2020).

\subsection{AR and $V R$}

In recent times, two main categories of technologies exist in the museums today: Augmented Reality (AR) and Virtual Reality (VR). AR influences the real world on a device screen, employing the camera of the device to create stunning images. The aim of AR is to recreate the presence of virtual objects in the real world, adding $2 \mathrm{D}$ or $3 \mathrm{D}$ objects to a real digital video image. AR objects are invisible to the eyes, a user has to connect via a display which can be a computer screen, a television, a smartphone or tablet (Cawood and Fiala, 2007). VR uses a computer graphics system and various interface devices, transporting the user into a completely artificial world and enabling them to observe the objects in a three-dimensional space in a timely and unconstrained manner, matching changes made by the user in the real world with that of the virtual world (Wang and Liu, 2019). 


\section{The Museum Experience}

Museum visitors do not buy the collections, the experience generated by the visit is what they pay for. According to Pine and Gilmore (2009), the realms of this experience include entertainment, education, escape and aesthetics. These experiences cannot be staged without the use of facilities and people.

Entertainment, as a form of experience, is one of the most developed and most common. Modern museums have incorporated sensory aspects which include sight, sound, and motion, making it possible for visitors to actively immerse themselves in the museum experience (Kotler and Kotler, 2007).

Education is a primary function of museums, which serve as an informal educational centre for disseminating knowledge on art, history, nature, science, and technology. The organisation of lectures, seminars, and workshops, with expert speakers in various fields makes the museum an embodiment of knowledge in the subject it specialises on. Edutainment - the fusion of education and entertainment- enables museums carry out dual responsibilities simultaneously.

Escapist experience weigh more than that of entertainment and educational. According to Pine and Gilmore (1999), the visitor is immersed in an array of activities.

Aestheticism experience: individual visitors immerse themselves in an event or environment to appreciate beautiful things that surround them (Pine and Gilmore, 2009). When a visitor makes use of the museum, it is these forms of experiences that are sought for. The ambience of the museum environment has to be architecturally pleasing, inviting and capable of exciting visitors.

In recent years, many museums have utilised the opportunity of using technology to reach out to people beyond their vicinities. By maintaining websites with varying degree of services, museums gained the ability to showcase images and information about their collections online as a foretaste to the visit. In an attempt to enhance the experience of users, the use of technology in museums goes beyond the need to support management operations through data collection (Sheldon, 1997).

The use of smart objects contributes, in no small measure, to the enhanced promotion of cultural heritage because users are made to benefit from more enjoyable experiences. This makes it more preferable to employ multimedia facilities which enable visitors to interrelate with the surrounding cultural environments and better acquire knowledge (Chianese and Piccialli, 2014).

Children are not left out in having enjoyable museum experiences. The essence of preserving cultural heritage is for the next generation to be able to learn from them. The use of interactive displays in heritage museums is a tool in attractive children to museums, as it is medium children can easily relate with. Interactive learning activities and installations encourage social engagements between visitors, promote creativity, and helps visitors retain information.

\section{The Role of Architecture in Enriching the Museum Experience}

Architecture, often misinterpreted as the mere packaging, outerwear, man-made skin serving the same function as a coat preventing wetness or rust, is in actuality, the definition of space, the structure of our world, with interior and exterior inseparable as obtained in the various systems of anatomy (Sirefman, 1999). Ambrose and Paine (2006) see the setting up of museums, alongside theatres, libraries, concert halls, archives, or cinemas, as a means of promoting tourism and an important contribution to the cultural infrastructure of a location. Built forms are typical of cultural ideologies and status, and museum architecture can alter a downtown cityscape. New museums are a powerful tool for urban regeneration, which must be attentive to its surroundings, connect to the local neighbourhood and be relevant to a specific community. They must present 
an architecture that is substantive and welcoming, whether they take the shape of an addition to an existing building, a renovation, insertion, fragment, or collage. A collection devoid of a public viewing space is just a collection, and vice versa. Contemporary post-urban museum architecture must be seen as a museum collection and should be both formed by culture and culturally formative as it is integral to the museum experience.

Sirefman (1999) agrees that technology has made the museum a place to be, but points out that the real transformative power that technology can offer the museum goes beyond flashy interactive amenities, but seeks it to be a resource for exciting new architectural possibilities, expanding the architect's vocabulary. Exploring technology as a design and building tool offers a design process, divorced from traditional structural principles, embracing the use of programs common in aeronautics, shipbuilding, and bridge and highway construction (such as was used in erecting Frank Gehry's Guggenheim in Bilbao), will have a lasting impact on the museum's physical appearance and its architecture.

David Fleming (2005) discovers that the point of marketing and publicity, image-building and branding is a preparation for people to make contact with the museum. His discovery points out to the idea of a psychological space in which you enter way before the visit or before deciding to take the visit. Guggenheim museum, Bilbao, as a cultural facility housed inside an iconic structure, enhanced Bilbao's visibility and value at an international level (Plaza, Haarich and Waldron 2012). The image of a fascinating building by Frank Gehry, heavily used by the mass media, creates a good name not through the exhibits but through its architecture (Caldwell, 2000). The image of the building has been used to attract tourists and investors. People got familiar with the museum even when they had no intention of visiting the Guggenheim. Thus, the architecture of the Guggenheim has been influential in accentuating attraction to the museum.

\section{Conclusion}

Evolution in museum display is perceived by many as a decline and estrangement from the main purposes of acquiring, preserving, conserving, researching, and displaying tangible and intangible evidences of human life, as entertainment and consumption interfere with the purity of the cultural experience (Fleming, 2005). Currently, process-based and interactive installations have brought about a change in the relationship between the art, physical space and the audience (Buskirk, 2005). Interactive exhibitions offer visitors an opportunity to connect with physical space, providing environments for reading exhibits. The architectural quality of these spaces creates the multi-dimensional layers of varying modes of communicating the exhibitions.

Architects when designing museums should recognise that the museum building is the first medium of display, in attracting visitors. New museums designs will need to consciously create media spaces, infusing interactive exhibition spaces with traditional display methods. The allocation of spaces should take into consideration the possibility of expansion, change of display media and services. Peripherals, cable trunks, sockets, and other hardware should be housed in separate spaces away from the sight of visitors. It will be unsightly for visitors to trip over cables and come in contact with cable trays except the museum's theme is focused on such.

Heritage and conserved buildings, which are fragile in nature due to restrictions in renovation and remodelling, may incorporate interactive display technology and spaces as annexes to preserve the integrity of the building. Caution must be taken in this regard as the introduction of certain forms of technology may render. As digital display technologies gain momentum, the physical spaces will be converted to media spaces, which will increase the function and relevance of museums in a contemporary society. 


\section{References}

Ambrose, T., \& Paine, C. (2006). Museum Basics. Routledge.

Antara, N., \& Sen, S. (2020, 11 28). The Impact of COVID-19 on the Museums and the Way Forward for Resilience. Journal Of International Museum Education, 02(01), 54-61.

Barbieri, L., Fabio, B., \& Muzzapa, M. (2017). Virtual Museum System Evaluation Through User Studies. Journal of Cultural Heritage, 101-108.

Buskirk, M. (2005). The Contingent Object of Contemporary Art. The MIT Press.

Caldwell, N. G. (2000). The Emergence of Museum Brands. International Journal of Arts Management, 2(3).

Cawood, S., \& Fiala, M. (2007). Augmented Reality: A Practical Guide, The Pragmatic Programmes. USA.

Chianese, A., \& Piccialli, F. (2014). Designing A Smart Museum: When Cultural Heritage Joins IoT. International Conference on Nect Generation Mobile Apps, Services and Technologies, (pp. 300-306). Oxford, UK.

Crane, S. (2006). The Conundrum of Ephmerality: Time, Memory and Museums. In S. Macdonald (Ed.), A Companion to Museum Studies (pp. 98-109). Blackwell Publishers.

Din, H., \& Hecht, P. (2007). The Digital Museum: A Think Guide. Washington DC: AAM.

Fleming, D. (2005). Creative Space. In S. Macleod (Ed.), Reshaping Museum Space: Architecture, Design, Exhibitions (pp. 53-61). London: Taylor \& Francis.

Kotler, N., \& Kotler, P. (2007). Can Museums be all things to all People? Missions, Goals, and Marketing's Roles. Museum Management and Curatorship, 3(28), 271-289.

Pine, B., \& Gilmore, J. (1999). The Experience Economy. Harvard Business School Press.

Plaza, B., Harrich, S. N., \& Waldon, C. (2012). Branding Bilbao: Assessing the Role of an Art Museum in Creating A Valuable Place Brand. ACEI 2012 - 17th International Conference on Cultural Economics. Kyoto.

Sfintes, A.-I. (2013, 12 7). The Architecture of Virtual Space Museums. European Scientific Journal (ESJ), 9(21).

Sheldon, K. (1997). What is Satisfying about Satisfying Events testing 10 Candidates? Psychological Needs? Journal of Personality and Social Psychology, 80(2), 325-339.

Sirefman, S. (1999). Formed and Forming: Contemporary Museum Acrhitecture. Daedalus, 128(3), 297-320.

Tallon, L., \& Walker, K. (2008). Digital Technologies and The Museum Experience. Plymouth: Altamira Press.

Wang, B., \& Liu, Y. (2019). The Research on Application of Virtual Reality Technology in Museums. Journal of Physics: Conf. Series. 